\title{
Erratum to: Ultrahigh dimensional variable selection through the penalized maximum trimmed likelihood estimator
}

\author{
N. M. Neykov • P. Filzmoser • P. N. Neytchev
}

Published online: 25 May 2013

(C) Springer-Verlag Berlin Heidelberg 2013

\section{Erratum to: Stat Papers \\ DOI 10.1007/s00362-013-0516-z}

The equation (15) and the text below it were incorrectly published:

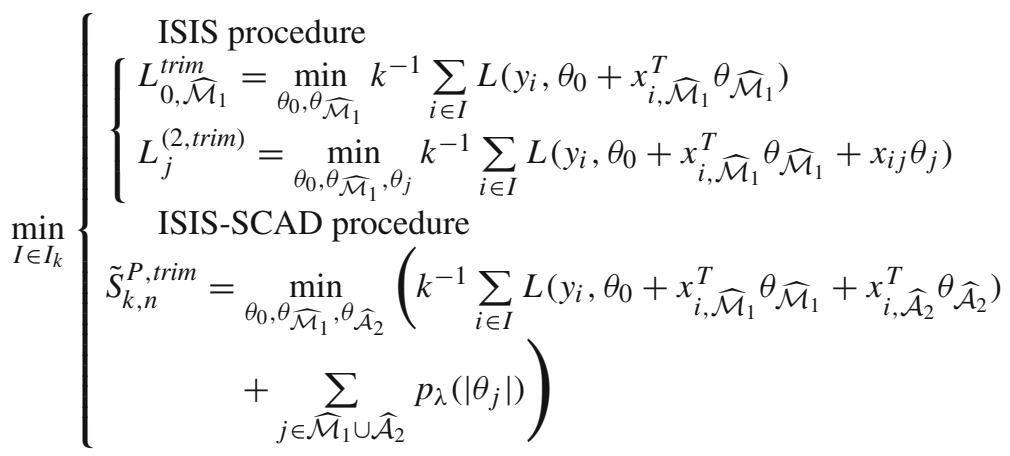

The online version of the original article can be found under doi:10.1007/s00362-013-0516-z.

N. M. Neykov $(\varangle) \cdot$ P. N. Neytchev

National Institute of Meteorology and Hydrology,

Bulgarian Academy of Sciences, Sofia, Bulgaria

e-mail: neyko.neykov@meteo.bg

P. N. Neytchev

e-mail: Plamen.Neytchev@meteo.bg

P. Filzmoser

Department of Statistics and Probability Theory,

Vienna University of Technology, Vienna, Austria

e-mail: P.Filzmoser@tuwien.ac.at 
Therefore, for all $k$-subsets the linked optimization problems (19)...

The correct version is given here:



Therefore, for all $k$-subsets the linked optimization problems (15)... 